they are threatened with destruction. According to the strategy, governments should consider the needs of conservation at all stages of development. As an example, the authors recommend that forestry should not be directed only towards increasing the yield of products and the provision of services such as recreation and education. Forest management must ensure that yields are sustainable, and genetic diversity is preserved. The preservation of genetic diversity in general is an immediate task for governments in order to prevent the extinction of further species of wildlife, crop plants and livestock, any of which could be needed in the future (for example, in agricultural breeding programmes or the production of drugs). The recommended approach is to preserve ecosystems intact within reserves, augmented by collections both of whole organisms, as in zoos and botanic gardens, and of genetic material such as seed and semen.

The preservation of genetic resources is also a priority for action by international agencies, which are called upon to provide a wide range of assistance such as that provided for crop plants by the International Board for Plant Genetic Resources. According to the strategy, financial assistance should also be sought from commercial enterprises that benefit from the exploitation of living resources.

Another international priority is action to halt the depletion of shared resources in oceans and river basins. The scale of losses also makes tropical forests and drylands a priority for international action. In the latter case, low rainfall, high rates of evaporation and inefficient use are encouraging the rapid spread of deserts. The strategy calls for the implementation of the wide ranging plan of action formulated at the UN Conference on Desertification in September, 1977.

The hazards that beset a scheme for environmental action, were well expressed by Mr Michael Heseltine, UK Secretary of State for the Environment, when he said at the launching ceremony in London:

"The basis of my approach - and indeed of the present government - rests on conservation, good husbandry and wise use of resources. But it would be less than frank of me to assert tht all decisions of government flow naturally and easily from that premise".

It is, he pointed out, almost always a matter of balancing a developmental need, often with a clear economic advantage, against a potential conservation loss. $\mathrm{Mr}$ Heseltine injected a further note of caution when Mr David Attenborough, naturalist and broadcaster, insisted that the people at large should compel governments everywhere to recognise the strategy, which must become a political issue. Otherwise, Attenborough said, it was doomed to be "just another abandoned lofty plan". He has set his fellow citizens a difficult task.

Mary Lindley

United Kingdom

\title{
Fast reactor fuel cycle to begin
}

THE United Kingdom Atomic Energy Authority has been given approval to make regular shipments of plutonium nitrate in water solution from Dounreay on the north coast of Scotland to Windscale in Cumbria, north-west England, as part of an experimental fast reactor fuel cycle. The nitrate will be the result of reprocessing of fuel elements from the Dounreay prototype fast reactor (PFR). For economic reasons the Authority plans to refabricate new fuel, perhaps by the 'sol gel' process, at Windscale rather than at Dounreay. Shipments will begin later this year, at the rate of one every two to four weeks.

Behind the decision may lie uncertainty about the future siting of the commercial demonstration fast reactor (CDFR) that the Authority would like to build. The government has promised a public enquiry on the fast breeder before any commitment is made to the CDFR, and only if it were to be built at Dounreay would it be economic to build a fuel fabrication plant there.

The shipments ultimately will be on a large scale, involving some $800 \mathrm{~kg}$ of

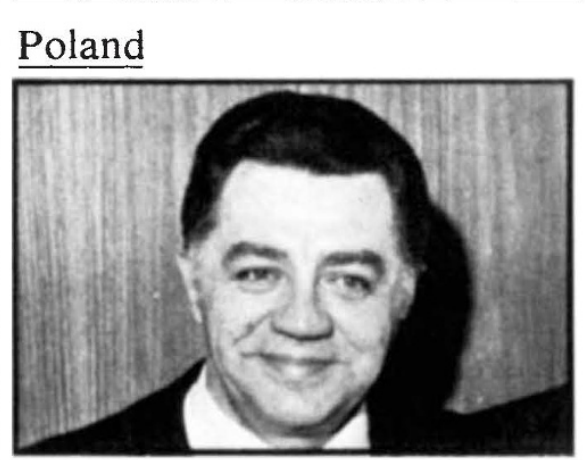

Bartosiewicz: power cooperation

\section{Energy agreement}

Mr Zbigniew Bartosiewicz, Polish Minister of Power and Atomic Energy has signed a cooperation agreement with Sir Francis Tombs, Chairman of The UK Electricity Council. The agreement covers the exchange of information and possible joint research on the more efficient use of conventional energy sources for power generation.

The Minister's five-day visit to the UK comes at a time when Poland's industrial expansion programme has outstripped generating capacity.

During his visit, Bartosiewicz attended a seminar organised by the Department of Industry, at which one of the major topics discussed was "down time" - the unscheduled stoppage of generating sets for maintenance work. UK participants in the seminar later reported that they felt the optimisation of maintenance logistics could well be a fruitful theme for cooperation. plutonium a year. Each load, carried in a specially designed 250 litre flask in a $27 \mathrm{~m}^{3}$ containment vessel, may amount to a critical mass of the metal - so the flask has had to be designed to minimise risk of criticality.

Another design problem has been the continuous radiolysis of water by alpha emission from the plutonium. This results in a build up of hydrogen and oxygen gas, in explosive proportions. An inert gas atmosphere is introduced to dilute the gas, and so reduce the risk of explosion.

"Nevertheless", says a Department of Energy note on the shipments, "assessments have been made of the possible consequences of gas ignition within the package"'.

The package is unlikely to be damaged in a transport accident sufficiently to breach the inner vessel, says the note. "However, if the vessel was ruptured, and in the further unlikely event that a source of ignition was present, and that the mixture of hydrogen and oxygen was in the explosive range, any resultant explosion internal or external to the containment vessel but inside the outer package would generate insufficient pressure to rupture the external structure."

The inner vessel is designed to withstand the pressure that, it is calculated, will build up in the vessel up to 250 days; then it is unlikely to rupture. The danger here is of a shipwreck, followed by a delay in recovery. The Authority has performed recovery tests on a dummy container hidden in a wreck off West Scotland, which "was found and retrieved in hours". However, tests have not been made on the time for which a damaged inner container (after a collision, say) would withstand pressure build-up.

In an impact test, however, there was cracking of the outer vessel and fracturing of the radiation shield. According to a report prepared by the Nuclear Installation Inspectorate, published last week "it can be argued that would give enhanced access to heat flux" in the case of an impact followed by fire. Although, said an Authority spokesman, "that was one we were a bit bothered about", the NII concluded that thermal tests that had been conducted (on an undamaged third-scale model) were "an adequate demonstration" of safety.

The greatest dangers may occur during the loading and unloading of the inner vessel to and from its impact-resistant container, where the Authority has assumed that the vessel would not survive a two-foot drop. But, says the Department of Energy, the Health and Safety Executive are satisfied, as a result of tests, that the vessel would survive such an impact.

Robert Waigate 